\title{
A Clinical Audit for Compliance on the Innovated Radiographic Technique at a Radiologic Unit
}

\author{
S. ISMANTO ${ }^{1 *}$ AND C.H. HASSAN $^{2}$
}

\begin{abstract}
This study identified X-ray laboratory users' compliance with the innovated radiographic technique and evaluated it's effectiveness in decreasing risks of repeating unnecessary X-ray exposure. The use of various steps in the standard operating procedures of radiography, proper radiographic technique and critique, practical protection measures, and radiographic positioning practice in X-ray laboratory at a private radiographic academy in Indonesia were audited. Thirty participants were used as the simple random sample. The demographic distribution was divided into, gender, nationality, and practical experience. Generally, out of 30 participants, 20 (67\%) complied, and $10(33 \%)$ did not. Radiograph image results showed that proper radiographic technique was effective in decreasing repetitive exposure among X-ray laboratory users.
\end{abstract}

Key words: Clinical audit; radiographic technique; X-ray laboratory; wrist joint; innovation; radiography

The steps in the standard operating procedures of radiography (Meschan 1979), proper radiographic technique (Brennan \& Johnston 2002), radiographic critiques (Mohd 2008), radiographic positioning practice and practical protection measures (Whitley et al. 2005), standard operating procedure of radiographic positioning practice in $\mathrm{X}$-ray laboratory radiologic academy - the innovated radiographic technique - were audited.

According to the National Institute for Clinical Excellence, clinical audit provides practitioners with a systematic response that compares the care provided to best practice while preserving the central role of the clinical team in agreeing and implementing plans for change (Excellence 2002).This study is necessary to be conducted in a private owned radiologic academy in Indonesia to make a good change in the system.
According to Jones and Cawthorn (2002), when a clinical audit is conducted well, it provides improved methods and systems (the innovated radiographic technique) in which the quality of procedure for service users becomes supportive and developmental. That is why the innovated radiographic technique for X-ray laboratories was anticipated to improve and develop the practice of radiographic technique among X-ray laboratory users.

This study hopes to improve the behaviour of radiographers whereby it also leads to an unbiased evaluation of the effectiveness of $\mathrm{X}$-ray laboratory users in decreasing the poor quality of radiological diagnostic images which as a result often leads to a repetition of shooting radiographs (Surić Mihić et al. 2008).

\footnotetext{
1 ATRO Nusantara, Indonesia

${ }^{2}$ Faculty of Nursing, Lincoln University College, Malaysia

* Corresponding author (e-mail: faizmanto78@gmail.com)
} 
Radiographers must follow the protocols and standards set by actively participating in establishing and further developing protocols to ensure consistency of diagnostic quality images and improved practices to reduce human radiation exposures (Herrmann et al. 2012).

Unlike in other professions where the purpose of the simulation is to practice procedures to minimize error, in medical imaging, there is great value in being able to visualize the effect of incorrect technique as this reinforces the importance of accurate positioning and allows reflection on corrective approaches (Bridge et al. 2014).

On account of these issues, this clinical audit aims to evaluate the compliance on the innovated radiographic technique among X-ray laboratory users in a private owned radiologic academy in Indonesia. In addition, it also aims to identify which demographic variables, such as gender, nationality and clinical practical experience which complies with the practice of the innovated radiographic technique. A conclusion is also offered.

\section{BACKGROUND}

Ionizing radiation may affect different living biological systems and organs such as gastrointestinal, central nervous systems, gonads or even whole body and result in somatic and genetic effects based on the number of exposures (Talab et al. 2016) (refer Table 1).

The Publication No. 732 of the International Commission on Radiological Protection (ICRP) recommended the use of diagnostic reference levels for patients who have undergone the common diagnostic procedure as a measure for the optimization of protection in medical exposures (Surić Mihić et al. 2008). The human users' exposure dosage may reduce up to $75 \%$ by complying with the appropriate imaging techniques (Talab et al. 2016).
Therefore, the ICRP recommendation can protect human users against radiation damage (Prasad et al. 2014).

The innovated radiographic technique is a quality improvement which spanned from the principles of the ICRP recommendations. Furthermore, by reviewing available literature, the author was able to validate the innovation which would lead to a more credible result.

Table 1. Ionizing radiation effects and their risk to humans (Talab et al. 2016)

\begin{tabular}{l|l}
\hline & \multicolumn{1}{|c}{ Deterministic/Non-stochastic } \\
\hline 1. & Skin erythema/necrosis/epilation \\
2. & Cataract \\
3. & Sterility \\
4. & Radiation sickness \\
5. & IUGR/teratogenesis/fetal death \\
\hline & \multicolumn{1}{|c}{ Stochastic } \\
\hline 1. & Cancer \\
2. & $\begin{array}{l}\text { Hereditary defect } \\
\text { (e.g. down syndrome) }\end{array}$ \\
\hline
\end{tabular}

\section{LITERATURE REVIEW}

The ICRP recommendations address the following:

(1) Proper positioning of the patient or his anatomic part on the central ray, proper choice of grid and cone, choice of screen (cassette) or non-screen technique;

(2) Choice of optimum exposure factors, removal of film from cassette in darkroom;

(3) Transfer of the film to hanger (for wet film developing) or to an autonomic processing unit, passage of film, either automatically or manually, through development, stopbath, fixation, wash and dry, sorting and attachment of dried films to the consultation request form and old film envelope, ready for interpretation by the radiologist; 
(4) Submission of consultation report to the referring physician; and

(5) Return of the duplicate report as well as the films to the appropriate files are the standard operating procedures (Figure 1) of radiography that is to be complied by radiographers (Meschan 1979).

When critiquing your radiograph (Step 2) it is useful to look at the aspects that make up a good image. One way to ensure that all areas are covered is to use an acronym such as: positioning; anatomy of interest; collimation; exposure factors; markers; normality/anomaly; and remote operators radiographic licensing (Mohd 2008).

Lastly, the operators carrying out the medical exposures are to take practical steps to protect the human users who may be involved in: preparation, identification, addressing particular issues, e.g. paediatrics, females, selection of imaging equipment, type of image receptor, patient positioning, exposure technique, image projection, beam collimation, exposure parameters, patient protective equipment and shielding (Whitley et al. 2005).

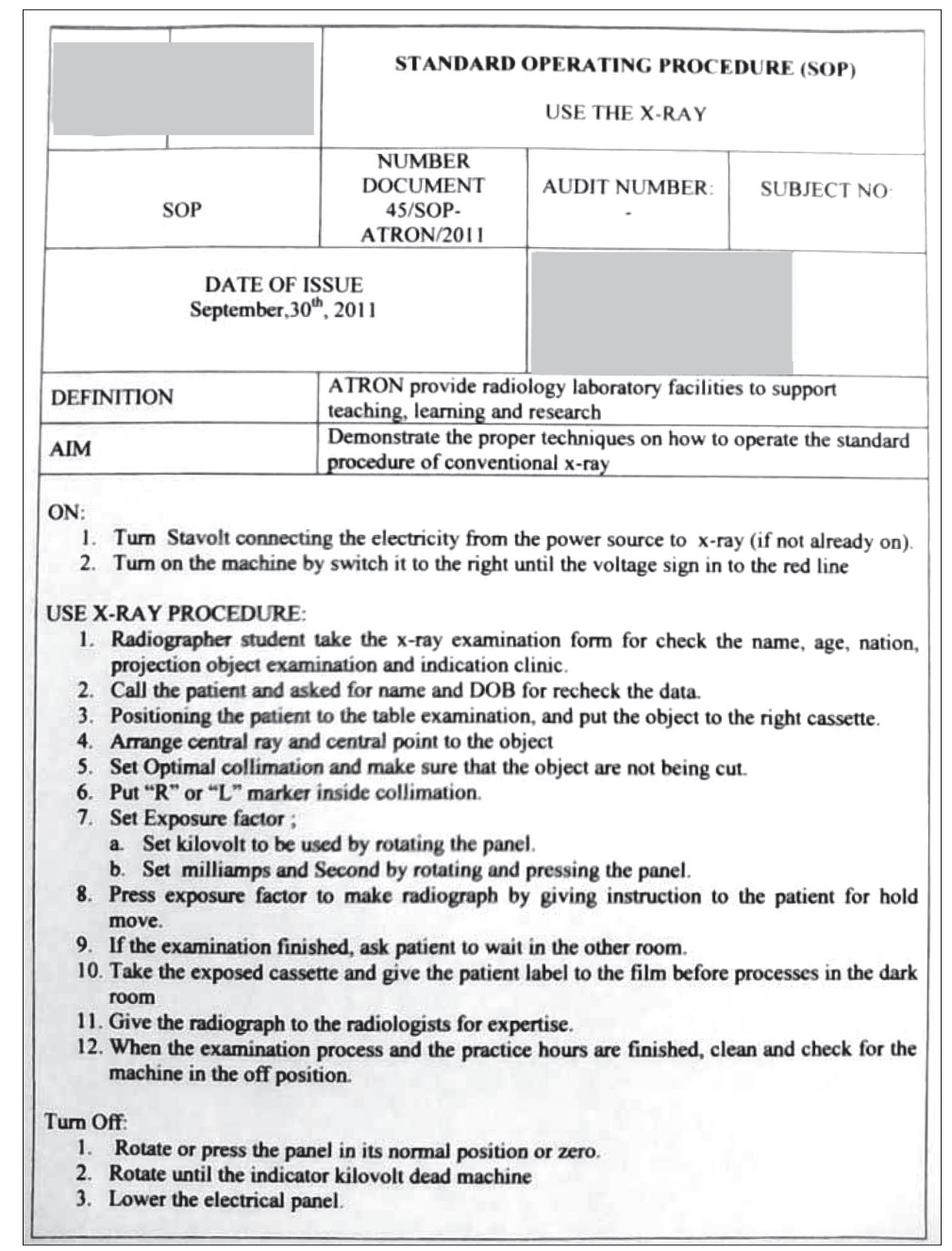

Figure 1. The innovated radiographic technique. 


\section{METHODOLOGY}

Primarily the auditors qualified as a radiographer evaluated the innovated radiographic technique. The participants involved in the audit are the $\mathrm{X}$-ray laboratory instructors and their students in semester four. A simple random sampling was used to select the subjects.

Secondly, the auditors ensured that the innovation was presented to the operations management for approval which was then shown to the deans to ensure that it was operational and in coordination with the lecturer's or X-ray laboratory instructor's schedule. The auditors also made sure that the $\mathrm{X}$-ray laboratories were supplied with facilities such as lead apron, marker placement, exposure factor chart, and the X-ray machine.

Steps of the innovated radiographic technique was posted on the walls of the selected laboratories with the seal of approval from the academy's operations management. The posters were $9.14 \mathrm{~cm}$ long, and $6.09 \mathrm{~cm}$ wide which was similar to A-3 sized papers and the letters were typed in big font size 40, written both in the Indonesian and English language. It was anticipated that the laboratory instructors would emphasize to their students to comply with the approved innovated radiographic techniques.

Finally, an additional risk of safety for human subjects was approved by the department of research and a copy to the operations management to commence the audit was given.

The audit was carried out for a maximum of 3 days. Since the auditor (in this case, the author) used ten radiographers and students in semester 4 , the total number of participants were 30 . The auditors ensured that the audit would not be repeated since the prospective subjects both students and teachers - were not informed that they were being observed.
Portfolios of the participants were organized and it was ensured that it followed the guidelines of the Quality Assurance Agency (Moore 2005). Each participant was given index numbers for data analysis. Each index number was given to the participants so that the portfolio would be easily accessed when they wished to refer to the results of their published findings in this clinical audit.

The auditor (the author) before starting the audit went into a console/control table room with a glass window and sat inside while observing the participants. The selected participants were anticipated to have no problems with the Indonesian/English language, encrypted on the innovated radiographic techniques posted on the walls.

Prospective subjects/participants who did not comply with the method of radiographic techniques was category used as non-compliance, while those who complied belonged to the category of compliance.

After the participants had used the X-ray laboratory, whether they complied with the procedure following the innovated radiographic techniques or not, were asked to process the $\mathrm{X}$-ray films in the dark room. This concluded the evaluation.

Steps in processing the films in the darkroom was not audited. The dark room in the place for film processing was ready to be used after the X-rays were done and the innovated radiographic techniques were performed.

The radiograph films after being processed in the dark room were collected and labeled as 'compliance' and 'non-compliance'. 


\section{FINDINGS}

Thirty participants were given the consent to be innovated in this audit procedure. The participants who belonged to the noncompliance category were evaluated to have miscommunicated the innovated standard radiographic techniques posted on the walls. Those who demonstrated all the steps of the innovation belonged to the compliance category.

Table 2, shows the identified demographic distribution of the 30 participants that were categorized as compliant and non-compliant with the innovated standard radiographic techniques in the X-ray laboratory. Out of 30 , there were more participants who complied $n=$ (20 or $67 \%$ ) than those who did not comply $n=$ (10 or $33 \%$ ).
The selected private academy had more participants who practiced in Central Hospital Governance as compared with those who did not.

According to Table 2, participants who were from female high school (science majors) complied most on the methods (six compliance), followed by those from male high school (social majors) (four compliance) and by the same gender as the vocational high school (2 compliance). There were more males who did not comply from the vocational high school (3 non-compliance) followed by the high school of social majors (2 non-compliance). While the females from high school science and social majors had more non-compliance $(2 / 30)$ followed by the participants from the vocational high school (1/30).

Table 2. The findings of both compliance and non-compliance to radiographic technique in the X-ray laboratory.

\begin{tabular}{c|cccccc}
\hline Categories & Male & Female & Jakarta & $\begin{array}{c}\text { Non- } \\
\text { Jakarta }\end{array}$ & $\begin{array}{c}\text { Practice in } \\
\text { Central } \\
\text { Hospital } \\
\text { Governance }\end{array}$ & $\begin{array}{c}\text { Non-practice } \\
\text { in Central } \\
\text { Hospital } \\
\text { Governance }\end{array}$ \\
\hline \multirow{3}{*}{ Compliance } & 5 & 6 & 7 & 4 & 9 & 2 \\
& 4 & 2 & 1 & 5 & 4 & 2 \\
Non- & 2 & 1 & 1 & 2 & 1 & 2 \\
compliance & 0 & 2 & 0 & 2 & 1 & 0 \\
& 2 & 2 & 1 & 3 & 3 & 3 \\
\hline
\end{tabular}

There were more non-locals of Jakarta who complied (11/30) as compared with those who were locals of Jakarta (9/30). The selected private academy had more locals of Jakarta as compared with the non-locals of Jakarta.

There were more subjects who practiced in Central Hospital Governance who complied $(14 / 30)$ as compared with those who did not $(6 / 30)$.
The statistical figures identified compliance of radiographic techniques in the $\mathrm{X}$-ray laboratory. Data analysis using percentage was appropriate for this clinical audit to easily convert a group of figures into one value and when it is dispersed into several values would still be easily averaged. The picture in Figure 2, is the result of a good compliance to proper positioning. 


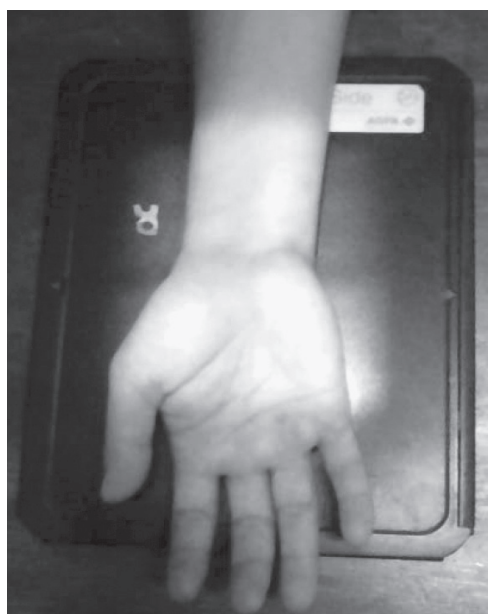

Figure 2. Radiographic technique of the wrist joint.

Figure 3, shows the comparison of compliance and non-compliance. A very few evidence of compliance was shown on the radiographic image films after being processed in the dark room.

\section{ACTION PLAN FOR CHANGE MANAGEMENT}

Planning how to communicate the posters was addressed to enhance the change management of the innovated procedure. Those who did not practice in Central Hospital Governance and who were non-compliant might have also experienced barriers in communication skills. Handbooks may be an action plan to change the communication process.

The innovated radiographic techniques audited in this private academy in Indonesia could use a handbook to enhance learning in the workplaces. However, the handbook should achieve the aim to provide an element of professional practice pertinent to reduce the errors on X-ray photo shooting. This would distinguish the challenges of implementing the innovation.

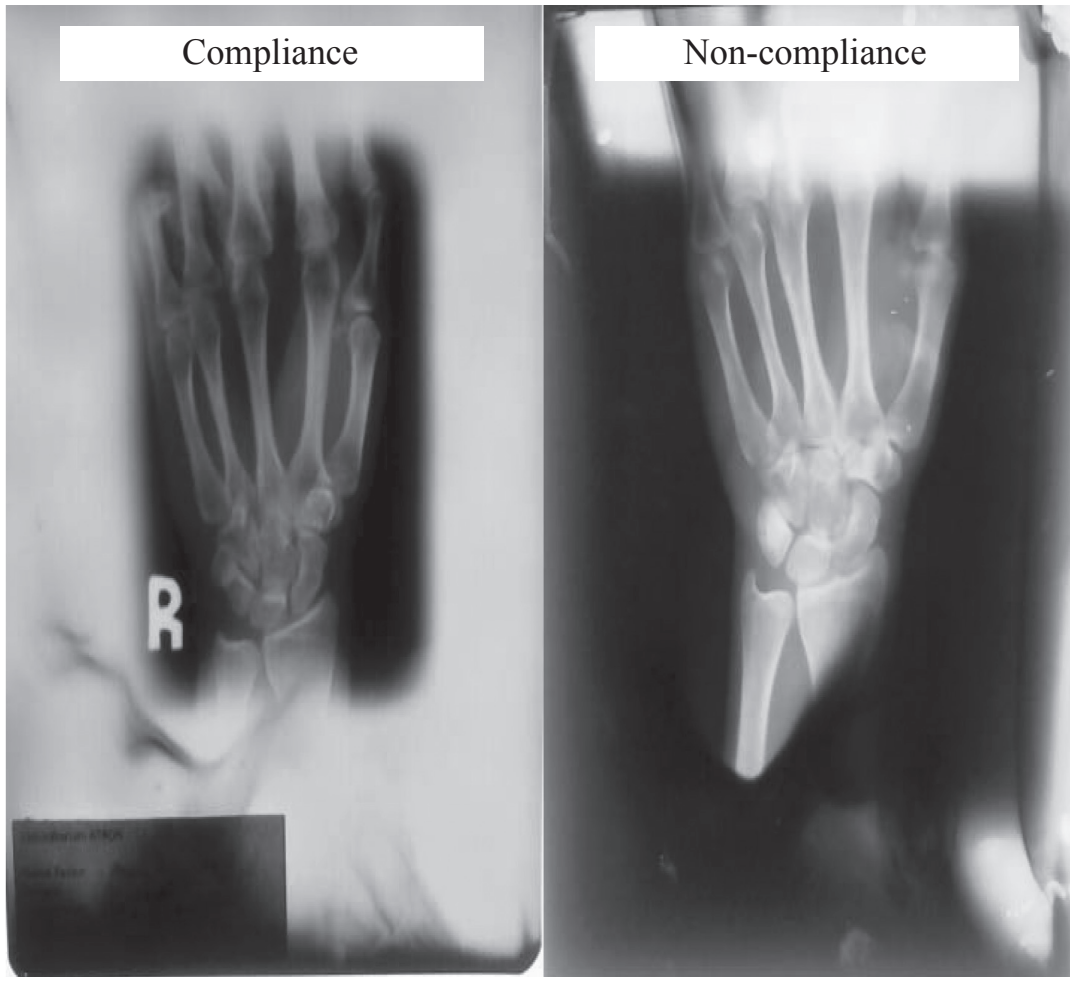

Figure 3. Comparison of compliance and non-compliance. 
Auditing the correct way by using the apparatuses to radiographic techniques was the primary step. However, the process of change could be threatened if the user did not have the full knowledge on how to operate the machine. In order to avoid this weakness, the auditors after conducting the audit could ensure that the standard operating procedures were explained to the X-ray laboratory users.

However, the observation started primarily without the participants knowing that they were being observed. This might perhaps be the reason why the students and instructors did not demonstrate competency in using the machine. own students who would use the laboratory at their workplaces after giving them seminars and training.

These laboratory users (whether they were students or laboratory instructors) would be identified as potential harm to the likely success of the change process if they did not comply with the innovated radiographic techniques in $\mathrm{X}$-ray laboratory after giving them seminars and training.

Hence, clinical audits should constantly be conducted semi-annually to freeze the change process (Table 3).

Table 3. The clinical audit that should constantly be conducted.

\begin{tabular}{|c|c|c|}
\hline $\begin{array}{l}\text { What we want them to do? } \\
\text { (Innovated radiographic techniques) }\end{array}$ & $\begin{array}{l}\text { What they are doing? } \\
\text { (Findings) }\end{array}$ & $\begin{array}{l}\text { What they need to do? } \\
\text { (Action plan) }\end{array}$ \\
\hline $\begin{array}{l}\text { Using Standard Operational } \\
\text { Procedure Laboratory }\end{array}$ & $\square$ Complied $\square$ Not complied & $\begin{array}{l}\text { Read the posters on the } \\
\text { walls }\end{array}$ \\
\hline $\begin{array}{l}\text { Steps in the production of } \\
\text { radiograph }\end{array}$ & $\square$ Complied $\square$ Not complied & $\begin{array}{l}\text { Read the handbook and } \\
\text { attend seminars and } \\
\text { training }\end{array}$ \\
\hline $\begin{array}{l}\text { Demonstrate the } \\
\text { PACEMAN }\end{array}$ & $\square$ Complied $\square$ Not complied & $\begin{array}{c}\text { Attend seminars and } \\
\text { training and disseminate } \\
\text { information }\end{array}$ \\
\hline
\end{tabular}

In order to evaluate the effectiveness of the innovation in making X-ray laboratory users to demonstrate competency in complying with the innovation, the auditors could give X-ray laboratory instructors seminars and trainings to emphasize on the innovated radiographic techniques.

It could be anticipated that the laboratory instructors would disseminate the information and their knowledge of the innovation to their

\section{CONCLUSION}

Out of the 30 participants, 16 were male participants and 14 were female participants. Of the 14 females, nine were compliant (64\%), and five were non-compliant (36\%). Of the 16 males, 11 were compliant (69\%), and five were non-compliant (31\%). It was also identified that factors affecting radiation dosage during radiographic examinations included applied 
tube voltage $(\mathrm{kVp})$, tube current $(\mathrm{mA})$, exposure time (s), filtration, focal spot to skin distance, film-screen speed, collimation, and patient size which was needed to be addressed among radiographers to take into consideration.

It was therefore concluded that auditing innovated radiographic techniques in X-ray laboratory was deemed necessary to identify and evaluate an unbiased outcome of X-ray quality image since radiographic techniques after using the X-ray laboratories decreased the risk of unnecessary harm to human users.

The innovated radiographic technique in X-ray laboratory was successful although this audit showed a percentage of deviation from the point of complete compliance due to communication barriers. More participants complied (20 or $67 \%$ ) than those who did not comply (10 or $33 \%)$.

A poor radiographic technique, in turn, might lead to unnecessary exposures to $\mathrm{X}$-radiation, poor image quality, repeated views and examinations, patient discomfort or further injury because of poor positioning and the possibility of a missed diagnosis or misdiagnosis. The knowledge of radiographers regarding optimal techniques in reducing unnecessary X-ray exposure by applying the recommended exposure protocols would be a foundation to reaffirm reducing the danger of cancer induction as far as possible during repeated X-rays examination. Improvement of the professional and public reputation of the radiological department as a result of education and active work approach is important.

\section{ACKNOWLEDGEMENT}

I would like to appreciate Regidor 111 for the valuable supervision rendered during the study.

Date of submission: June 2016 Date of acceptance: September 2016

\section{REFERENCES}

Brennan, P \& Johnston, D 2002, 'Irish X-ray departments demonstrate varying levels of adherence to European guidelines on good radiographic technique', The British Journal of Radiology, vol. 75, no. 891, pp. 243-248.

Bridge, P, Gunn, T, Kastanis, L, Pack, D, Rowntree, P, Starkey, D \& Wilson-Stewart, K 2014, 'The development and evaluation of a medical imaging training immersive environment', Journal of Medical Radiation Sciences, vol. 61, no. 3, pp. 159-165.

Excellence, NIfC 2002, Principles for best practice in clinical audit, Radcliffe Publishing.

Herrmann, TL, Fauber, TL, Gill, J, Hoffman, C, Orth, DK, Peterson, PA \& Odle, TG 2012, 'Best practices in digital radiography', Radiologic Technology, vol. 84, no. 1, pp. 83-89.

Jones, T \& Cawthorn, S 2002, 'What is a clinical audit', Evidence Based Medicine, Hayward Medical Communications.

Meschan, I 1979, Radiographic positioning and related anatomy, WB Saunders Company.

Mohd, MN 2008, Pocketbook guide to radiographic image evaluation, University Publication Centre.

Moore, L 2005, 'Professional portfolios: a powerful vehicle for reflective exercises and recording work-based learning', Journal of Work Based Learning in Primary Care, vol. 4, pp. 25-35.

Prasad, K, Cole, W \& Haase, G 2014, 'Radiation protection in humans: extending the concept of as low as reasonably achievable (ALARA) from dose to biological damage', The British Journal of Radiology, vol. 77, no. 917, pp. 97-99

Surić Mihić, M, Meštrović, T, Prlić, I \& Surić, D 2008, 'Importance of quality assurance program implementation in conventional diagnostic radiology', 
Collegium Antropologicum, vol. 32, no. 2, pp. 181-184.

Talab, AHD, Mahmodi, F, Aghaei, H, Jodaki, L \& Ganji, D 2016, 'Evaluation of the effect of individual and demographic factors on awareness, attitude and performance of radiographers regarding principles of radiation protection', Al Ameen J. Med. Sc., vol. 9, no. 2, pp. 90-95.

Whitley, AS, Sloane, C, Hoadley, G \& Moore, AD 2005, Clark's positioning in radiography, 12th edn., CRC Press. 